\title{
Quantitative Proteomics Analysis by Isobaric Tags for Relative and Absolute Quantitation Identified Lumican as a Potential Marker for Acute Aortic Dissection
}

\author{
Guorong Gu, ${ }^{1}$ Weizhong Cheng, ${ }^{1}$ Chenling Yao, ${ }^{1}$ Jun Yin, ${ }^{1}$ Chaoyang Tong, ${ }^{1}$ Andrew Rao, \\ Lawrence Yen, ${ }^{2}$ Matthew $\mathrm{Ku},{ }^{2}$ and Jianyu $\mathrm{Rao}^{2}$ \\ ${ }^{1}$ Zhongshan Hospital, Shanghai Medical College, Fudan University, Shanghai 200032, China \\ ${ }^{2}$ Department of Pathology and Laboratory Medicine, UCLA School of Medicine, Los Angeles, CA 90095, USA
}

Correspondence should be addressed to Chenling Yao, yao.chenling@zs-hospital.sh.cn

Received 6 September 2011; Revised 27 October 2011; Accepted 27 October 2011

Academic Editor: Saulius Butenas

Copyright (C) 2011 Guorong Gu et al. This is an open access article distributed under the Creative Commons Attribution License, which permits unrestricted use, distribution, and reproduction in any medium, provided the original work is properly cited.

\begin{abstract}
Acute aortic dissection (AAD) is a serious vascular disease. Currently the diagnosis relies on clinical and radiological means whereas serum biomarkers are lacking. The purpose of this study was to identify potential serum biomarkers for AAD using isobaric tags for relative and absolute quantitation (iTRAQ) approach. A total of 120 serum samples were collected from three groups: AAD patients $(n=60)$, patients with acute myocardial infarction (AMI, $n=30)$, and healthy volunteers $(n=30)$, whereas the first 10 samples from each group were used for iTRAQ analysis. Using iTRAQ approach, a total of 174 proteins were identified as significantly different between AAD patients and healthy subjects. Among them, forty-six proteins increased more than twofold, full-scale analysis using serum sample for the entire 120 subjects demonstrated that Lumican level was significantly increased relative to control and AMI samples. Further, Lumican level correlated with time from onset to admission in AAD but not AMI samples. Using iTRAQ approach, our study showed that Lumican may be a potential AAD-related serum marker that may assist the diagnosis of AAD.
\end{abstract}

\section{Introduction}

Acute aortic dissection (AAD) has become a treatable disease due to recent advances in new therapeutic approaches for the management of heart and arterial diseases; however, development of quick and economic diagnostic methods remains a challenge. Variability in disease presentation often obscures diagnoses, and imaging modalities such as computed tomography (CT), magnetic resonance imaging (MRI), and esophagus ultrasound remain prohibitive due to cost and availability. Aortic dissection remains a frequent target of medicolegal litigations with accusations of failure to diagnose against treating physicians and hospitals [1]. Some progress in the biochemical diagnosis of AAD has been made in the last decade $[2,3]$; several acute phase proteins and coagulation parameters were identified to increase in $\mathrm{AAD}$ patients, but these are nonspecific biomarkers for $\mathrm{AAD}$ as they may be also aberrantly expressed in other disease conditions such as acute myocardial infarction (AMI).

Recently a quantitative proteomic assay, isobaric tags for relative and absolute quantitation (iTRAQ), has been developed and utilized to identify biomarkers for various disease conditions $[4,5]$. This chemical labeling method involves the stable incorporation of isotopes into an amine tagging reagent, which can then be reliably detected by mass spectrometry, thereby permitting comparative quantitation of various proteins in a multiplex manner. It has been suggested to be suitable for the discovery of biomarkers in a wide range of body fluids and tissues, including serum and plasma $[5,6]$. With this method, we expect to find the potential biomarkers which are released from the disruption of the aortic media and can provide sufficient specificity and longer time window for the diagnosis of AAD. 


\section{Materials and Methods}

2.1. Samples. The study included a total of 30 healthy individuals and 90 patients (60 AAD, $30 \mathrm{AMI})$. All the patients were selected in a consecutive manner from the period of July 2009 to November 2011 from Fudan University affiliated Zhongshan Hospital (Shanghai, China). iTRAQ analysis was performed for the first twenty patients (10 AAD and 10 AMI) and ten healthy individuals. All patients presented within 72 hours after an episode of chest and/or back pain lasting 5 minutes or more. The diagnosis of AAD was confirmed by computed tomographic arteriography (CTA). The AMI patient was confirmed by electrocardiography (ECG) and cardiac troponin T (cTNT) tests. All patients gave their informed consent for the study. The protocol was approved by the Ethics Committee of Zhongshan Hospital.

For each study subject, whole blood samples were immediately collected in BD Vacutainer SST tubes (BD Diagnostics, Plymouth, UK) after admission and centrifuged at $4000 \mathrm{rpm}$ for $10 \mathrm{~min}$ at room temperature. The serum was frozen and stored in aliquots at $-80^{\circ} \mathrm{C}$ until analysis.

2.2. Serum C-Reactive Protein and Myoglobin Test. Vitros 5.1 FS automatic biochemistry analyzer (Johnson \& Johnson; Calif, USA) was used for serum C-reactive protein (CRP) test, and Cobas e411 immunoassay analyzer (Roche; Mannheim, Germany) was used for the serum myoglobin (Myo) test. The results were then interpreted in accordance with that tested by the International Federation of Clinical Chemistry (IFCC) recommended method. Analyses were performed immediately after the centrifugation of whole blood samples.

\section{3. iTRAQ Sample Preparation: Strong Cation Exchange} (SCX) Chromatography. iTRAQ reagents were purchased from Applied Biosystems (Foster City, USA). Fourteen interfering highly abundant proteins from serum samples were removed using Agilent multiple affinity removal liquid chromatography (LC) column-Human 14 (MARS) (shimadzu, Kyoto, Japan). One hundred micrograms of each extract were precipitated using acetone at $-20^{\circ} \mathrm{C}$ and suspended in $20 \mu \mathrm{L}$ of dissolution buffer (Applied Biosystems, Foster City, USA). After reduction and alkylation, each sample was digested with trypsin $(\mathrm{w}($ trypsin $): \mathrm{w}($ protein $)=1: 20)$ at $37^{\circ} \mathrm{C}$ overnight. The tryptic peptides were labeled with the iTRAQ reagents as follows: normal controls group was labeled with iTRAQ 113, AMI group was labeled with iTRAQ 114, and AAD group was labeled with iTRAQ 115. The peptides were pooled and desalted with Sep-Pak Vac C18 (Waters, Milford, USA). The peptide mixture was diluted with buffer A containing $10 \mathrm{mM} \mathrm{KH}_{2} \mathrm{PO}_{4}$ in $25 \%$ acetonitrile (ACN) at $\mathrm{pH}$ 2.6. The peptides were fractionated by 20AD high-performance liquid chromatography (HPLC) system (Shimadzu; Kyoto, Japan) equipped with a polysulfoethyl A column $(2.1 \mathrm{~mm} \times 100 \mathrm{~mm}, 5 \mathrm{u}, 200 \mathrm{~A}$; The Nest Group, Southborough, Mass). The composition of buffer B was $350 \mathrm{mM} \mathrm{KCl}, 10 \mathrm{mM} \mathrm{KH} \mathrm{PO}_{4}$, and $25 \% \mathrm{ACN}$ at $\mathrm{pH}$ 2.6. Separation was performed using a linear binary gradient of
$0-80 \%$ buffer B in buffer $A$ at a flow rate of $200 \mu \mathrm{L} / \mathrm{min}$ for $60 \mathrm{~min}$. The fractions were combined into 20 groups.

2.4. LC-MS Analysis. Each SCX fraction was dried down by the rotary vacuum concentrator, dissolved in buffer $\mathrm{C}(0.1 \%$ formic acid, 5\% ACN, 95\% water), and analyzed on Qstar XL (Applied Biosystems; Foster City, USA). The HPLC gradient was 5-35\% buffer D (95\% ACN, 0.1\% formic acid) in buffer $\mathrm{C}$ at a flow rate of $300 \mathrm{~nL} / \mathrm{min}$ for $70 \mathrm{~min}$. Analysis survey scans were acquired MS from $\mathrm{m} / \mathrm{z} 400-1800$ with up to 4 precursors selected for MS/MS from m/z 100-2000.

2.5. The Confirmative ELISA Analysis for Lumican. The confirmative ELISA analysis for Lumican was performed using the kits from CUSABIO BIOTECH CO, following manufacture's recommendation (CUSABIO BIOTECH CO., LTD., Wuhan, China).

2.6. Data Analysis. All statistical analyses were performed in SPSS 12.0 (SPSS Inc. Chicago, USA). Results were presented as Mean \pm SD. A comparative analysis of multiple groups was performed with a one-way-ANOVA or MannWhitney/Kruskal-Wallis Test. Statistical significance was defined as $P<0.05$. Peptide and protein identification was performed by searching the MS/MS spectra against the SwissProt database using the local Protein Pilot 2.0.1 software. Only peptides identified with confidence interval values of no less than 95\% (Unused ProtScore $>1.3$ ) were used for protein identification compilation and subsequent quantitation calculation. Fold changes of $>2$ or $<0.5$ were set as cut-off values to designate significant differences in protein expression among the AAD group and the normal control group.

2.7. PANTHER Analysis. The PANTHER database was used to elucidate cellular components, biological processes, and the molecular functions associated with each individual protein (http://www.pantherdb.org/).

\section{Results}

3.1. Clinical Features of Study Subjects. The clinical features of the AAD patients, AMI patients, and normal controls are summarized in Table 1. There were no differences in age distribution and sex composition among the three groups involved either for ELISA analysis $(N=120)(P=0.351$ and 0.378 , resp.) $)$ or iTRAQ analysis ( $P=0.241$ and 0.873 , resp.). There was no differences in the time from onset to admission between AAD and AMI group either $(P=0.776)$.

3.2. Functional Classification of Identified Proteins by iTRAQ. A total of 174 proteins with confidence interval values of no less than 95\% were identified (Unused ProtScore > 1.3). However, after manually rechecking the MS/MS data thoroughly peak by peak, 155 proteins $(89.08 \%)$ had a relative quantitation of one or more peptides. Fifteen proteins had no quantifiable peptides that could be ascertained, and four 
TABLE 1: Clinical characteristics in three groups.

\begin{tabular}{|c|c|c|c|c|c|}
\hline & & $\mathrm{AAD}$ & AMI & $\begin{array}{l}\text { Normal } \\
\text { controls }\end{array}$ & $P$ value \\
\hline & $n$ & 60 & 30 & 30 & \\
\hline \multirow{7}{*}{$\begin{array}{l}\text { ELISA test } \\
(N=120)\end{array}$} & Age $($ Mean \pm SD $)$ & $55.63 \pm 16.39$ & $59.70 \pm 13.98$ & $59.50 \pm 12.65$ & $0.351^{\mathrm{a}}$ \\
\hline & $\begin{array}{l}\text { Gender, } n(\%) \\
\text { male }\end{array}$ & $30(50)$ & $17(56.67)$ & $16(53.33)$ & $0.378^{\mathrm{b}}$ \\
\hline & $\begin{array}{c}\text { Admission after } \\
\text { onset hours } \\
(\text { Mean } \pm \text { SD) }\end{array}$ & $20.19 \pm 18.09$ & $19.33 \pm 15.31$ & I & $0.776^{\mathrm{c}}$ \\
\hline & Type A $n(\%)$ & $31(51.67)$ & l & l & \\
\hline & Type B $n(\%)$ & $29(48.33)$ & I & I & \\
\hline & Marfan $n(\%)$ & $7(11.67)$ & 1 & 1 & \\
\hline & $n$ & 10 & 10 & 10 & \\
\hline \multirow{6}{*}{$\begin{array}{l}\text { iTRAQ test } \\
(N=30)\end{array}$} & Age $($ Mean \pm SD) & $51.60 \pm 13.22$ & $61.00 \pm 5.25$ & $49.9 \pm 15.02$ & $0.241^{\mathrm{a}}$ \\
\hline & $\begin{array}{l}\text { Gender, } n(\%) \\
\text { male }\end{array}$ & $6(60)$ & $6(60)$ & $5(50)$ & $0.873^{\mathrm{b}}$ \\
\hline & $\begin{array}{l}\text { Admission after } \\
\text { onset hours } \\
(\text { Mean } \pm \text { SD) }\end{array}$ & $27.20 \pm 24.56$ & $18.40 \pm 23.12$ & I & $0.363^{c}$ \\
\hline & Type A $n(\%)$ & $5(50)$ & I & I & \\
\hline & Type B $n(\%)$ & $5(50)$ & I & I & \\
\hline & Marfan $n(\%)$ & $2(20)$ & I & I & \\
\hline
\end{tabular}

${ }^{\mathrm{a}}$ One-way-ANOVA; ${ }^{\mathrm{b}}$ Chi-square Test; ${ }^{\mathrm{c}}$ Mann-Whitney Test.

proteins had peptides with confidence interval values that were less than $95 \%$.

In total, 174 proteins were sorted using the PANTHER classification system, which sorts the proteins into respective categories based on their molecular functions. The major groups include: signaling molecules (13\%), enzyme modulators $(12 \%)$, transfer/carrier proteins $(11 \%)$, and proteases $(10 \%)$. Other groups include: structural proteins $(1 \%)$, cell adhesion molecules (1\%), cytoskeletal proteins (3\%), extracellular matrix proteins ( $2 \%)$, and cell junction proteins (1\%).

As a way to cross-check the reliability of quantitation of iTRAQ reagent, serum CRP and Myo levels were assessed using both conventional biochemical and immunoassay tests and ITRAQ analysis on the same specimens. With biochemical and immunoassay analysis, CRP was $41.31 \pm$ $32.76 \mathrm{mg} / \mathrm{mL}$ and Myo was $66.42 \pm 81.23 \mathrm{mg} / \mathrm{mL}$ in AAD group, while in normal controls, the former was $5.88 \pm$ 1.42 and the latter was $32.07 \pm 14.14 \mathrm{mg} / \mathrm{mL}$. CRP and Myo levels of AAD patients were 7.03-fold and 2.07-fold higher, respectively, than normal controls. Using iTRAQ, the AAD/normal controls ratios of CRP and Myo were similar at 9.12-fold (Table 2) and 1.47-fold. The ratios of CRP and Myo among three groups were similar with either biochemical and immunoassay or iTRAQ analysis, confirming the reliability of iTRAQ analysis.

3.3. Proteins with Over Twofold Differential Expression. A total of 155 proteins had a relative quantitation difference for $\mathrm{AAD}$ patients compared with the normal control group of which 46 proteins increased more than twofold (Table 2), while 36 proteins decreased more than twofold among the AAD patients (Table 3 ). Among the identified proteins with increased levels in $\mathrm{AAD}$, there were a number of acute phase reactants (CRP, Beta-2-microglobulin, Complement factor I), blood coagulation marker (Haptoglobin, Coagulation factor V, Coagulation factor IX), and cellular components (Lumican, Tubulin beta-3 chain, Fibronectin). However when compared to AMI patients, 14 of the 46 protein showed less than 2-fold increase, including complement component 9, complement factor1, Plasma protein $\mathrm{C} 1$ inhibitor, and Ig Kappa chain C-region (Table 2). Interestingly, some acute phase proteins such as CRP remains on the list as it showed the differential expression between the two conditions.

Among proteins with decreased expression in AAD patients compared with normal controls, there were a number of molecules involved in protein metabolism (Interalpha-trypsin inhibitor heavy chain H2, Alpha-2-HSglycoprotein), lipid metabolic process (Apolipoprotein A-IV, Apolipoprotein E, Apolipoprotein C-I), blood coagulation marker (Fibrinogen alpha chain, Prothrombin), and cellular components (Alpha-2-HS-glycoprotein, thrombospondin-1 (TSP-1)). When compared to AMI patients, 8 of 36 proteins did not reach the 2 -fold differential expression (Table 3 ).

3.4. The ELISA Analysis of Serum Concentrations of Lumican. Based on the iTRAQ findings above we selected two targets, Fibronectin and Lumican, the protein markers potentially associated with vascular injury, for the validation using ELISA method. At the initial analysis using $10 \mathrm{AAD}$ and 10 normal samples we found that statistical significant difference between AAD and normal individual was seen for 
TABLE 2: List of the increased ( $>2$-fold) protein targets identified and their corresponding class, associated biological process, and cellular component.

\begin{tabular}{|c|c|c|c|c|c|c|c|c|c|}
\hline $\mathrm{N}$ & Unused $^{a}$ & Peptides ${ }^{b}$ & Accession \# & Name & $\begin{array}{l}\text { Biological } \\
\text { process }\end{array}$ & $\begin{array}{l}\text { Cellular } \\
\text { component }\end{array}$ & Protein class & $\begin{array}{l}\mathrm{AAD} / \mathrm{CON} \\
\text { ratio }\end{array}$ & $\begin{array}{l}\mathrm{AAD} / \mathrm{AMI} \\
\text { ratio }\end{array}$ \\
\hline 1 & 2.7 & 1 & Q13509 & $\begin{array}{l}\text { Tubulin beta-3 } \\
\text { chain }\end{array}$ & $\begin{array}{c}\text { Cellular } \\
\text { component } \\
\text { morphogenesis }\end{array}$ & Cytoskelelton & $\begin{array}{c}\text { Cytoskeletal } \\
\text { protein/tubulin }\end{array}$ & 39.8406 & 0.0711 \\
\hline 2 & 2 & 1 & P01600 & $\begin{array}{l}\text { Ig kappa chain } \\
\text { V-I region Hau }\end{array}$ & & & Unclassified & 31.3480 & 3.0760 \\
\hline 3 & 6.67 & 3 & P02743 & $\begin{array}{l}\text { Serum amyloid } \\
\text { P-component }\end{array}$ & $\begin{array}{l}\text { Response to } \\
\text { stress }\end{array}$ & & $\begin{array}{c}\text { Defense/immunity } \\
\text { pro- } \\
\text { tein/antibacterial } \\
\text { response }\end{array}$ & 24.4499 & 9.1241 \\
\hline 4 & 13.53 & 10 & P05546 & $\begin{array}{c}\text { Heparin cofactor } \\
2\end{array}$ & $\begin{array}{l}\text { Protein } \\
\text { metabolic } \\
\text { process }\end{array}$ & & Enzyme modulator & 19.7628 & 11.2740 \\
\hline 5 & 17.67 & 9 & P36955 & $\begin{array}{l}\text { Pigment } \\
\text { epithelium- } \\
\text { derived } \\
\text { factor }\end{array}$ & $\begin{array}{l}\text { Protein } \\
\text { metabolic } \\
\text { process }\end{array}$ & & Enzyme modulator & 19.7628 & 9.8135 \\
\hline 6 & 6.24 & 4 & P05543 & $\begin{array}{l}\text { Thyroxine- } \\
\text { binding } \\
\text { globulin }\end{array}$ & $\begin{array}{l}\text { Protein } \\
\text { metabolic } \\
\text { process }\end{array}$ & & Enzyme modulator & 12.7065 & 3.7665 \\
\hline 7 & 12.63 & 18 & P01834 & $\begin{array}{l}\text { Ig kappa chain } \mathrm{C} \\
\text { region }\end{array}$ & $\begin{array}{l}\text { Response to } \\
\text { stimulus }\end{array}$ & $\begin{array}{l}\text { Immunoglobulin } \\
\text { complex }\end{array}$ & $\begin{array}{l}\text { Defense/immunity } \\
\text { protein }\end{array}$ & 11.6959 & 1.8031 \\
\hline 8 & 55.14 & 43 & P02751 & Fibronectin & $\begin{array}{c}\text { Blood } \\
\text { coagulation }\end{array}$ & $\begin{array}{l}\text { Extracellular } \\
\text { matrix }\end{array}$ & $\begin{array}{c}\text { Transfer/carrier } \\
\text { protein }\end{array}$ & 11.5875 & 3.7327 \\
\hline 9 & 35.94 & 29 & P01011 & $\begin{array}{l}\text { Alpha-1- } \\
\text { antichymotrypsin }\end{array}$ & $\begin{array}{l}\text { Protein } \\
\text { metabolic } \\
\text { process }\end{array}$ & & Enzyme modulator & 10.5708 & 8.0906 \\
\hline 10 & 2.22 & 1 & P02741 & $\begin{array}{l}\text { C-reactive } \\
\text { protein }\end{array}$ & $\begin{array}{l}\text { Response to } \\
\text { stress }\end{array}$ & & $\begin{array}{l}\text { Defense/immunity } \\
\text { protein }\end{array}$ & 9.1241 & 5.9701 \\
\hline 11 & 2 & 1 & Q9UK55 & $\begin{array}{c}\text { Protein } \\
\text { Z-dependent } \\
\text { protease inhibitor }\end{array}$ & $\begin{array}{l}\text { Protein } \\
\text { metabolic } \\
\text { process }\end{array}$ & & Enzyme modulator & 8.7873 & 2.4888 \\
\hline 12 & 100.78 & 51 & P04114 & $\begin{array}{l}\text { Apolipoprotein } \\
\text { B-100 }\end{array}$ & $\begin{array}{l}\text { Lipid } \\
\text { metabolic } \\
\text { process }\end{array}$ & & $\begin{array}{c}\text { Transfer/carrier } \\
\text { protein }\end{array}$ & 8.6281 & 2.8050 \\
\hline 13 & 9.19 & 4 & P35858 & $\begin{array}{l}\text { Insulin-like } \\
\text { growth } \\
\text { factor-binding } \\
\text { protein complex } \\
\text { acid labile chain }\end{array}$ & $\begin{array}{l}\text { Cell-cell } \\
\text { adhesion }\end{array}$ & $\begin{array}{l}\text { Extracellular } \\
\text { matrix }\end{array}$ & Receptor & 8.4746 & 4.0177 \\
\hline 14 & 47.88 & 42 & P19827 & $\begin{array}{l}\text { Inter-alpha- } \\
\text { trypsin inhibitor } \\
\text { heavy chain H1 }\end{array}$ & $\begin{array}{l}\text { Protein } \\
\text { metabolic } \\
\text { process }\end{array}$ & & Enzyme modulator & 5.8072 & 5.6497 \\
\hline 15 & 106.72 & 89 & P00450 & Ceruloplasmin & $\begin{array}{c}\text { Blood } \\
\text { coagulation }\end{array}$ & $\begin{array}{l}\text { Extracellular } \\
\text { matrix }\end{array}$ & Transporter & 5.1046 & 9.6339 \\
\hline 16 & 37.56 & 23 & P04196 & $\begin{array}{l}\text { Histidine-rich } \\
\text { glycoprotein }\end{array}$ & $\begin{array}{c}\text { Blood } \\
\text { coagulation }\end{array}$ & & Unclassified & 4.6125 & 3.2206 \\
\hline 17 & 4.15 & 2 & P08571 & $\begin{array}{c}\text { Monocyte } \\
\text { differentiation } \\
\text { antigen CD14 }\end{array}$ & $\begin{array}{c}\text { Immune } \\
\text { system process }\end{array}$ & & Receptor & 4.0933 & 2.4888 \\
\hline 18 & 2.72 & 1 & Q96KN2 & $\begin{array}{l}\text { Beta-Ala-His } \\
\text { dipeptidase }\end{array}$ & $\begin{array}{l}\text { Protein } \\
\text { metabolic } \\
\text { process }\end{array}$ & & Protease & 4.0933 & 1.9231 \\
\hline 19 & 31.66 & 20 & P01871 & $\begin{array}{l}\text { Ig mu chain } \mathrm{C} \\
\text { region }\end{array}$ & $\begin{array}{l}\text { Response to } \\
\text { stimulus }\end{array}$ & & $\begin{array}{l}\text { Defense/immunity } \\
\text { protein }\end{array}$ & 3.8023 & 2.3552 \\
\hline
\end{tabular}


Table 2: Continued.

\begin{tabular}{|c|c|c|c|c|c|c|c|c|c|}
\hline $\mathrm{N} \mathrm{L}$ & Unused $^{\mathrm{a}}$ & Peptides $^{\mathrm{b}}$ & Accession \# & Name & $\begin{array}{l}\text { Biological } \\
\text { process }\end{array}$ & $\begin{array}{c}\text { Cellular } \\
\text { component }\end{array}$ & Protein class & $\begin{array}{l}\mathrm{AAD} / \mathrm{CON} \\
\text { ratio }\end{array}$ & $\begin{array}{l}\mathrm{AAD} / \mathrm{AMI} \\
\text { ratio }\end{array}$ \\
\hline 20 & 12.12 & 6 & P51884 & Lumican & $\begin{array}{l}\text { Cell-cell } \\
\text { adhesion }\end{array}$ & $\begin{array}{l}\text { Extracellular } \\
\text { matrix }\end{array}$ & Receptor & 3.6311 & 1.2942 \\
\hline 21 & 2.71 & 1 & P00740 & $\begin{array}{l}\text { Coagulation } \\
\text { factor IX }\end{array}$ & $\begin{array}{c}\text { Blood } \\
\text { coagulation }\end{array}$ & & Protease & 3.4037 & 2.0137 \\
\hline 22 & 6.27 & 3 & P08185 & $\begin{array}{l}\text { Corticosteroid- } \\
\text { binding } \\
\text { globulin }\end{array}$ & $\begin{array}{l}\text { Protein } \\
\text { metabolic } \\
\text { process }\end{array}$ & & Enzyme modulator & 3.2808 & 5.4945 \\
\hline 23 & 2.58 & 21 & P00739 & $\begin{array}{l}\text { Haptoglobin- } \\
\text { related } \\
\text { protein }\end{array}$ & & & Unclassified & 3.2206 & 1.7538 \\
\hline 24 & 4.98 & 4 & P04003 & $\begin{array}{l}\text { C4b-binding } \\
\text { protein alpha } \\
\text { chain }\end{array}$ & $\begin{array}{c}\text { Blood } \\
\text { coagulation }\end{array}$ & & $\begin{array}{c}\text { Transfer/carrier } \\
\text { protein }\end{array}$ & 3.1626 & 5.0582 \\
\hline 25 & 6.02 & 6 & P02745 & $\begin{array}{l}\text { Complement C1q } \\
\text { subcomponent } \\
\text { subunit A }\end{array}$ & $\begin{array}{l}\text { Response to } \\
\text { stimulus }\end{array}$ & & $\begin{array}{c}\text { Transfer/carrier } \\
\text { protein }\end{array}$ & 3.1046 & 3.6982 \\
\hline 26 & 5.83 & 3 & P22792 & $\begin{array}{l}\text { Carboxypeptidase } \\
\text { N subunit } 2\end{array}$ & Cell adhesion & $\begin{array}{l}\text { Extracellular } \\
\text { matrix }\end{array}$ & Receptor & 3.0202 & 1.3805 \\
\hline 27 & 15.99 & 11 & P05155 & $\begin{array}{l}\text { Plasma protease } \\
\text { C1 inhibitor }\end{array}$ & $\begin{array}{l}\text { Protein } \\
\text { metabolic } \\
\text { process }\end{array}$ & & Enzyme modulator & 2.9647 & 1.2824 \\
\hline 28 & 2.02 & 2 & P01742 & $\begin{array}{l}\text { Ig heavy chain V-I } \\
\text { region EU }\end{array}$ & & & Unclassified & 2.8580 & 1.1695 \\
\hline 29 & 2 & 1 & P09486 & SPARC & $\begin{array}{l}\text { Cell-cell } \\
\text { signaling }\end{array}$ & & $\begin{array}{l}\text { Transfer/carrier } \\
\text { protein }\end{array}$ & 2.7042 & 0.7312 \\
\hline 30 & 18.06 & 9 & P02760 & Protein AMBP & $\begin{array}{c}\text { Blood } \\
\text { coagulation }\end{array}$ & & Enzyme modulator & 2.6062 & 3.5651 \\
\hline 31 & 8.99 & 5 & P12259 & $\begin{array}{l}\text { Coagulation } \\
\text { factor } \mathrm{V}\end{array}$ & $\begin{array}{c}\text { Blood } \\
\text { coagulation }\end{array}$ & $\begin{array}{l}\text { Extracellular } \\
\text { matrix }\end{array}$ & Transporter & 2.6062 & 3.2206 \\
\hline 32 & 8.31 & 6 & P27169 & $\begin{array}{c}\text { Serum paraox- } \\
\text { onase/arylesterase } \\
1\end{array}$ & $\begin{array}{l}\text { Immune } \\
\text { system process }\end{array}$ & & Oxidoreductase & 2.5349 & 5.6497 \\
\hline 33 & 2.32 & 1 & P19320 & $\begin{array}{c}\text { Vascular cell } \\
\text { adhesion protein } \\
1\end{array}$ & $\begin{array}{l}\text { Cell-cell } \\
\text { adhesion }\end{array}$ & & $\begin{array}{l}\text { Defense/immunity } \\
\text { protein }\end{array}$ & 2.3121 & 2.1478 \\
\hline 34 & 2.01 & 1 & O00187 & $\begin{array}{l}\text { Mannan-binding } \\
\text { lectin serine } \\
\text { protease } 2\end{array}$ & $\begin{array}{l}\text { Response to } \\
\text { stimulus }\end{array}$ & & Protease & 2.3121 & 1.5277 \\
\hline 35 & 43.19 & 29 & P02749 & $\begin{array}{c}\text { Beta-2- } \\
\text { glycoprotein } \\
1\end{array}$ & $\begin{array}{c}\text { Blood } \\
\text { coagulation }\end{array}$ & & $\begin{array}{c}\text { Transfer/carrier } \\
\text { protein }\end{array}$ & 2.2287 & 7.1124 \\
\hline 36 & 3.52 & 2 & P11226 & $\begin{array}{c}\text { Mannose-binding } \\
\text { protein } C\end{array}$ & $\begin{array}{l}\text { Response to } \\
\text { stimulus }\end{array}$ & & $\begin{array}{l}\text { Defense/immunity } \\
\text { protein }\end{array}$ & 2.2080 & 2.6062 \\
\hline 37 & 87.93 & 67 & P00738 & Haptoglobin & $\begin{array}{c}\text { Blood } \\
\text { coagulation }\end{array}$ & & Protease & 2.1678 & 3.5651 \\
\hline 38 & 5.7 & 4 & Q13790 & Apolipoprotein F & $\begin{array}{l}\text { Lipid } \\
\text { metabolic } \\
\text { process }\end{array}$ & & Transporter & 2.1478 & 3.9448 \\
\hline 39 & 65.42 & 41 & P02790 & Hemopexin & $\begin{array}{l}\text { Vitamin } \\
\text { transport }\end{array}$ & & $\begin{array}{l}\text { Transfer/carrier } \\
\text { protein }\end{array}$ & 2.1478 & 3.9078 \\
\hline 40 & 2.96 & 1 & P20851 & $\begin{array}{l}\text { C4b-binding } \\
\text { protein beta } \\
\text { chain }\end{array}$ & $\begin{array}{c}\text { Blood } \\
\text { coagulation }\end{array}$ & & $\begin{array}{l}\text { Transfer/carrier } \\
\text { protein }\end{array}$ & 2.1281 & 4.8309 \\
\hline
\end{tabular}


TABle 2: Continued.

\begin{tabular}{|c|c|c|c|c|c|c|c|c|c|}
\hline $\mathrm{N} \mathrm{L}$ & Unused $^{\mathrm{a}}$ & Peptides ${ }^{b}$ & Accession \# & Name & $\begin{array}{l}\text { Biological } \\
\text { process }\end{array}$ & $\begin{array}{c}\text { Cellular } \\
\text { component }\end{array}$ & Protein class & $\begin{array}{c}\mathrm{AAD} / \mathrm{CON} \\
\text { ratio }\end{array}$ & $\begin{array}{l}\mathrm{AAD} / \mathrm{AMI} \\
\text { ratio }\end{array}$ \\
\hline 41 & 2 & 1 & P61769 & $\begin{array}{c}\text { Beta-2- } \\
\text { microglobulin }\end{array}$ & $\begin{array}{l}\text { Response to } \\
\text { stimulus }\end{array}$ & & $\begin{array}{c}\text { Defense/immunity } \\
\text { protein }\end{array}$ & 2.1088 & 2.1281 \\
\hline 42 & 20.86 & 10 & P02748 & $\begin{array}{l}\text { Complement } \\
\text { component C9 }\end{array}$ & $\begin{array}{l}\text { Response to } \\
\text { stimulus }\end{array}$ & & Receptor & 2.1088 & 0.6252 \\
\hline 43 & 6.96 & 3 & P07477 & Trypsin-1 & $\begin{array}{l}\text { Protein } \\
\text { metabolic } \\
\text { process }\end{array}$ & & Protease & 2.1088 & 0.3436 \\
\hline 44 & 13.64 & 7 & P05156 & $\begin{array}{l}\text { Complement } \\
\text { factor I }\end{array}$ & $\begin{array}{l}\text { Response to } \\
\text { stimulus }\end{array}$ & & Protease & 2.0325 & 0.9120 \\
\hline 45 & 15.17 & 10 & P01842 & $\begin{array}{l}\text { Ig lambda chain } \\
\text { C regions }\end{array}$ & $\begin{array}{l}\text { Response to } \\
\text { stimulus }\end{array}$ & $\begin{array}{l}\text { Immunoglobulin } \\
\text { complex }\end{array}$ & $\begin{array}{l}\text { Defense/immunity } \\
\text { protein }\end{array}$ & 2.0137 & 2.1678 \\
\hline 46 & 4.29 & 1 & P35030 & Trypsin-3 & $\begin{array}{c}\text { Protein } \\
\text { metabolic } \\
\text { process }\end{array}$ & & Protease & 2.0137 & 1.3931 \\
\hline
\end{tabular}

${ }^{\mathrm{a}}$ Unused > 1.3 means at least $95 \%$ confidence; ${ }^{\mathrm{b}}$ number of peptides with $95 \%$ confidence; AAD: acute aortic dissection; AMI: acute myocardial infarction; CON: normal controls.

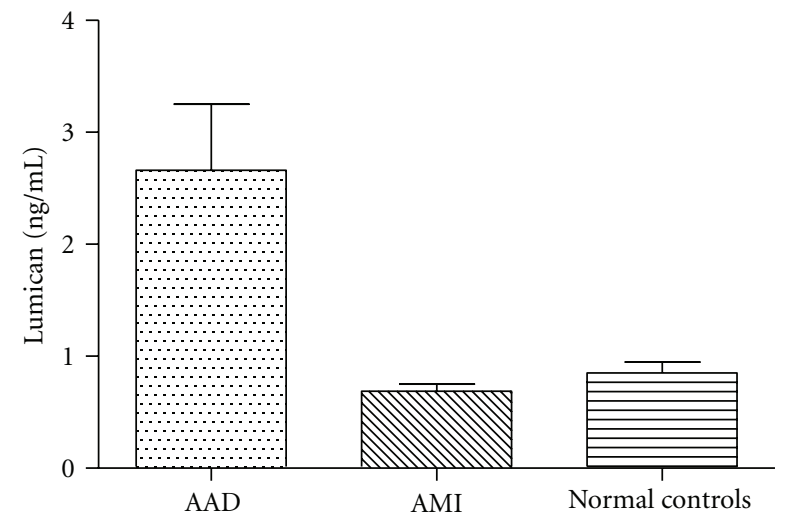

FIGURE 1: Lumican levels were significant difference between AAD, AMI, and normal individuals (Mean \pm SEM; $P=0.003$ ).

Lumican but not Fibronectin (data not shown). Therefore, we carried a full validation study only for Lumican, using the entire 120 samples collected (see Table 1). A statistical significant difference between AAD, AMI, and normal individual was seen in serum concentrations of Lumican $(2.66 \pm 4.58 \mathrm{ng} / \mathrm{mL}$ in AAD group, $0.69 \pm 0.34 \mathrm{ng} / \mathrm{mL}$ in AMI group, and $0.85 \pm 0.53 \mathrm{ng} / \mathrm{mL}$ in normal control, $P=0.003)$. The difference for AAD and AMI also reached statistical significance $(P<0.05)$ suggesting the specificity of this marker for AAD (Figure 1). We further analyzed the correlation between Lumican levels with time from onset of symptoms to admission. As shown in Figure 2, a correlation was seen in AAD group $(r=0.256, P=0.048)$ but not in AMI group ( $r=0.077, P=0.685)$, further confirming the specificity of Lumican as a marker for AAD.

\section{Discussion}

iTRAQ analysis is recently been used as a potentially more effective biomarker discovery method than traditional

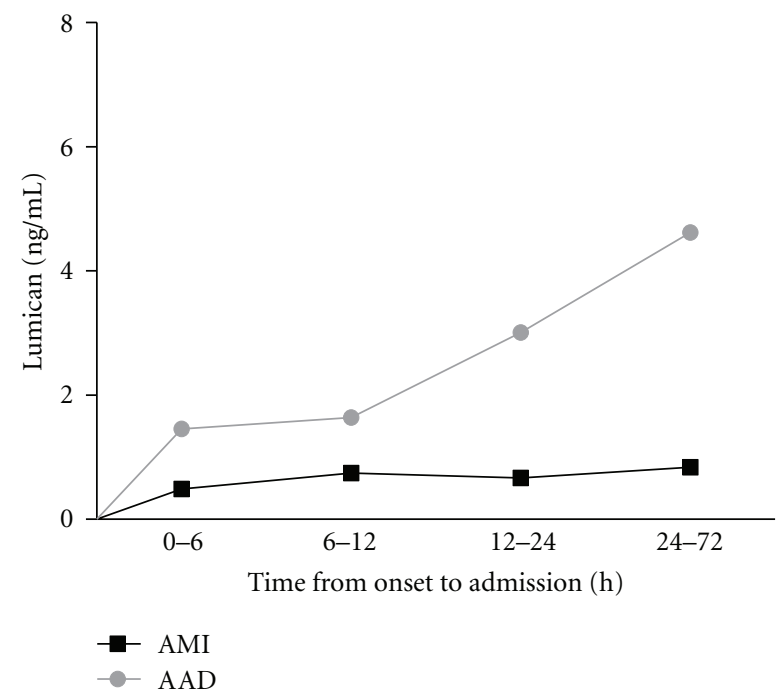

FIGURE 2: Lumican levels were correlation with time from onset to admission in AAD group $(r=0.256, P=0.048)$, but not in AMI group $(r=0.077, \quad P=0.685)$.

proteomic methods. The high reproducibility optimizes this technique for embarking on "fishing-expeditions" as an initial screening for potential useful biomarkers [6-8]. As a means of internal validation, the iTRAQ method was compared with CRP biochemical assay and Myo immunoassay. In our study there were no significant differences in the serum levels determined by the different methods. Thus, the iTRAQ method we employed appears in this preliminary analysis to be suitable for the detection of relevant proteins.

To identify differentially expressed proteins, in many studies, the cut-off points were set at $20 \%$ to $50 \%$ average variance $[7,9,10]$. However, such approaches may result in finding markers with low specificity $[2,3]$. We therefore appropriated to increase the cut-off point at $100 \%$ variance 
TABLE 3: List of the decreased ( $<0.5$ folds) protein targets identified and their corresponding class, associated biological process, and cellular component.

\begin{tabular}{|c|c|c|c|c|c|c|c|c|c|}
\hline $\mathrm{N} \mathrm{I}$ & Unused $^{\mathrm{a}}$ & Peptides ${ }^{b}$ & Accession \# & Name & $\begin{array}{l}\text { Biological } \\
\text { process }\end{array}$ & $\begin{array}{c}\text { Cellular } \\
\text { component }\end{array}$ & $\begin{array}{c}\text { Protein } \\
\text { classification }\end{array}$ & $\begin{array}{c}\mathrm{AAD} / \mathrm{CON} \\
\text { ratio }\end{array}$ & $\begin{array}{l}\mathrm{AAD} / \mathrm{AMI} \\
\text { ratio }\end{array}$ \\
\hline 1 & 19.31 & 17 & P02775 & $\begin{array}{c}\text { Platelet basic } \\
\text { protein }\end{array}$ & $\begin{array}{c}\text { Blood } \\
\text { coagulation }\end{array}$ & & $\begin{array}{c}\text { Transfer/carrier } \\
\text { protein }\end{array}$ & 0.0209 & 0.0398 \\
\hline 2 & 44.6 & 31 & P02671 & $\begin{array}{l}\text { Fibrinogen alpha } \\
\text { chain }\end{array}$ & $\begin{array}{c}\text { Blood } \\
\text { coagulation }\end{array}$ & $\begin{array}{l}\text { Extracellular } \\
\text { matrix }\end{array}$ & $\begin{array}{c}\text { Transfer/carrier } \\
\text { protein }\end{array}$ & 0.0370 & 0.0203 \\
\hline 3 & 19.82 & 30 & P02656 & $\begin{array}{l}\text { Apolipoprotein } \\
\text { C-III }\end{array}$ & $\begin{array}{l}\text { Lipid } \\
\text { metabolic } \\
\text { process }\end{array}$ & & Transporter & 0.0570 & 0.0240 \\
\hline 4 & 5.7 & 5 & P01717 & $\begin{array}{l}\text { Ig lambda chain } \\
\text { V-IV region Hil }\end{array}$ & & & Unclassified & 0.0655 & 0.0679 \\
\hline 5 & 8.45 & 4 & P02768 & Serum albumin & Transport & & $\begin{array}{c}\text { Transfer/carrier } \\
\text { protein }\end{array}$ & 0.0724 & 0.8472 \\
\hline 6 & 3.22 & 1 & P04264 & $\begin{array}{l}\text { Keratin, type II } \\
\text { cytoskeletal } 1\end{array}$ & $\begin{array}{c}\text { Cellular } \\
\text { component } \\
\text { morphogenesis }\end{array}$ & Cytoskelelton & Structural protein & 0.0780 & 0.9639 \\
\hline 7 & 2.05 & 1 & P04070 & $\begin{array}{l}\text { Vitamin } \\
\text { K-dependent } \\
\text { protein C }\end{array}$ & $\begin{array}{c}\text { Blood } \\
\text { coagulation }\end{array}$ & & Protease & 0.0794 & 0.0441 \\
\hline 8 & 34.98 & 27 & P02652 & $\begin{array}{l}\text { Apolipoprotein } \\
\text { A-II }\end{array}$ & $\begin{array}{l}\text { Lipid } \\
\text { metabolic } \\
\text { process }\end{array}$ & & Transporter & 0.0991 & 0.1067 \\
\hline 9 & 20.3 & 10 & P02654 & $\begin{array}{l}\text { Apolipoprotein } \\
\text { C-I }\end{array}$ & $\begin{array}{l}\text { Lipid } \\
\text { metabolic } \\
\text { process }\end{array}$ & & Transporter & 0.1159 & 0.0847 \\
\hline 10 & 94.94 & 108 & P02765 & $\begin{array}{l}\text { Alpha-2-HS- } \\
\text { glycoprotein }\end{array}$ & $\begin{array}{l}\text { Protein } \\
\text { metabolic } \\
\text { process }\end{array}$ & $\begin{array}{l}\text { Extracellular } \\
\text { matrix }\end{array}$ & $\begin{array}{l}\text { Extracellular } \\
\text { matrix protein }\end{array}$ & 0.1180 & 0.1472 \\
\hline 11 & 39.07 & 25 & P01008 & Antithrombin-III & $\begin{array}{l}\text { Protein } \\
\text { metabolic } \\
\text { process }\end{array}$ & & $\begin{array}{l}\text { Enzyme } \\
\text { modulator }\end{array}$ & 0.1202 & 0.0973 \\
\hline 12 & 72.69 & 57 & P00734 & Prothrombin & $\begin{array}{c}\text { Blood } \\
\text { coagulation }\end{array}$ & & $\begin{array}{l}\text { Enzyme } \\
\text { modulator }\end{array}$ & 0.1225 & 0.2051 \\
\hline 13 & 6.88 & 3 & P27918 & Properdin & $\begin{array}{l}\text { Response to } \\
\text { stimulus }\end{array}$ & & Unclassified & 0.1419 & 0.1905 \\
\hline 14 & 6.31 & 4 & P69905 & $\begin{array}{l}\text { Hemoglobin } \\
\text { subunit alpha }\end{array}$ & $\begin{array}{c}\text { Blood } \\
\text { circulation }\end{array}$ & & $\begin{array}{c}\text { Transfer/carrier } \\
\text { protein }\end{array}$ & 0.1500 & 0.2312 \\
\hline 15 & 8.97 & 15 & Q03591 & $\begin{array}{l}\text { Complement } \\
\text { factor H-related } \\
\text { protein } 1\end{array}$ & $\begin{array}{c}\text { Blood } \\
\text { coagulation }\end{array}$ & & $\begin{array}{c}\text { Transfer/carrier } \\
\text { protein }\end{array}$ & 0.1706 & 0.0991 \\
\hline 16 & 27.03 & 22 & P10909 & Clusterin & Apoptosis & & Unclassified & 0.1905 & 0.1076 \\
\hline 17 & 2 & 1 & Q15942 & Zyxin & $\begin{array}{c}\text { Cellular } \\
\text { component } \\
\text { morphogenesis }\end{array}$ & & $\begin{array}{l}\text { Enzyme } \\
\text { modulator }\end{array}$ & 0.1923 & 0.2109 \\
\hline 18 & 20.4 & 26 & P01024 & Complement C3 & $\begin{array}{l}\text { Protein } \\
\text { metabolic } \\
\text { process }\end{array}$ & & $\begin{array}{c}\text { Transfer/carrier } \\
\text { protein }\end{array}$ & 0.2070 & 0.1406 \\
\hline 19 & 7.43 & 3 & P17936 & $\begin{array}{l}\text { Insulin-like } \\
\text { growth } \\
\text { factor-binding } \\
\text { protein } 3\end{array}$ & $\begin{array}{l}\text { Cell-matrix } \\
\text { adhesion }\end{array}$ & & Unclassified & 0.2089 & 0.3162 \\
\hline 20 & 2.23 & 2 & P55290 & Cadherin-13 & $\begin{array}{l}\text { Cell-cell } \\
\text { adhesion }\end{array}$ & Cell junction & Receptor & 0.2188 & 0.1660 \\
\hline 21 & 1.41 & 1 & P13598 & $\begin{array}{c}\text { Intercellular } \\
\text { adhesion molecule } \\
2\end{array}$ & $\begin{array}{l}\text { Cell-cell } \\
\text { adhesion }\end{array}$ & & $\begin{array}{c}\text { Transfer/carrier } \\
\text { protein }\end{array}$ & 0.2355 & 0.1600 \\
\hline
\end{tabular}


Table 3: Continued.

\begin{tabular}{|c|c|c|c|c|c|c|c|c|c|}
\hline $\mathrm{N}$ & Unused $^{a}$ & Peptides $^{\mathrm{b}}$ & Accession \# & Name & $\begin{array}{c}\text { Biological } \\
\text { process }\end{array}$ & $\begin{array}{c}\text { Cellular } \\
\text { component }\end{array}$ & $\begin{array}{c}\text { Protein } \\
\text { classification }\end{array}$ & $\begin{array}{c}\mathrm{AAD} / \mathrm{CON} \\
\text { ratio } \\
\end{array}$ & $\begin{array}{l}\mathrm{AAD} / \mathrm{AMI} \\
\text { ratio }\end{array}$ \\
\hline 22 & 96.24 & 64 & P00751 & $\begin{array}{l}\text { Complement } \\
\text { factor B }\end{array}$ & $\begin{array}{c}\text { Blood } \\
\text { coagulation }\end{array}$ & & $\begin{array}{c}\text { Transfer/carrier } \\
\text { protein }\end{array}$ & 0.2466 & 0.2729 \\
\hline 23 & 28.82 & 16 & P09871 & $\begin{array}{l}\text { Complement C1s } \\
\text { subcomponent }\end{array}$ & $\begin{array}{c}\text { Blood } \\
\text { coagulation }\end{array}$ & & Protease & 0.2606 & 0.4169 \\
\hline 24 & 13.74 & 9 & P01019 & Angiotensinogen & $\begin{array}{l}\text { Protein } \\
\text { metabolic } \\
\text { process }\end{array}$ & & $\begin{array}{l}\text { Enzyme } \\
\text { modulator }\end{array}$ & 0.2630 & 0.5058 \\
\hline 25 & 95.34 & 74 & P19823 & $\begin{array}{l}\text { Inter-alpha- } \\
\text { trypsin inhibitor } \\
\text { heavy chain H2 }\end{array}$ & $\begin{array}{l}\text { Protein } \\
\text { metabolic } \\
\text { process }\end{array}$ & & $\begin{array}{l}\text { Enzyme } \\
\text { modulator }\end{array}$ & 0.2805 & 0.5649 \\
\hline 26 & 5.15 & 2 & P18065 & $\begin{array}{l}\text { Insulin-like } \\
\text { growth } \\
\text { factor-binding } \\
\text { protein } 2\end{array}$ & $\begin{array}{l}\text { Cell-matrix } \\
\text { adhesion }\end{array}$ & & Unclassified & 0.2884 & 0.3281 \\
\hline 27 & 16.84 & 10 & P07996 & $\begin{array}{c}\text { Thrombospondin- } \\
1\end{array}$ & $\begin{array}{c}\text { Blood } \\
\text { coagulation }\end{array}$ & $\begin{array}{l}\text { Extracellular } \\
\text { matrix }\end{array}$ & $\begin{array}{c}\text { Transfer/carrier } \\
\text { protein }\end{array}$ & 0.3404 & 0.8317 \\
\hline 28 & 5.31 & 3 & P26927 & $\begin{array}{c}\text { Hepatocyte } \\
\text { growth factor-like } \\
\text { protein }\end{array}$ & $\begin{array}{c}\text { Blood } \\
\text { coagulation }\end{array}$ & & $\begin{array}{c}\text { Transfer/carrier } \\
\text { protein }\end{array}$ & 0.3436 & 0.3436 \\
\hline 29 & 7.85 & 4 & O14791 & Apolipoprotein L1 & $\begin{array}{l}\text { Lipid } \\
\text { metabolic } \\
\text { process }\end{array}$ & & Transporter & 0.3908 & 0.2831 \\
\hline 30 & 94.76 & 57 & P06727 & $\begin{array}{c}\text { Apolipoprotein } \\
\text { A-IV }\end{array}$ & $\begin{array}{l}\text { Lipid } \\
\text { metabolic } \\
\text { process }\end{array}$ & & Transporter & 0.4018 & 0.1837 \\
\hline 31 & 14.1 & 9 & P35527 & $\begin{array}{l}\text { Keratin, type I } \\
\text { cytoskeletal } 9\end{array}$ & $\begin{array}{c}\text { Cellular } \\
\text { component } \\
\text { morphogenesis }\end{array}$ & & Structural protein & 0.4055 & 0.7244 \\
\hline 32 & 9.48 & 6 & P00746 & $\begin{array}{l}\text { Complement } \\
\text { factor D }\end{array}$ & $\begin{array}{c}\text { Blood } \\
\text { coagulation }\end{array}$ & & Protease & 0.4571 & 0.6668 \\
\hline 33 & 48.09 & 24 & P02649 & Apolipoprotein E & $\begin{array}{l}\text { Lipid } \\
\text { metabolic } \\
\text { process }\end{array}$ & & Transporter & 0.4656 & 0.2051 \\
\hline 34 & 38.8 & 32 & P02735 & $\begin{array}{l}\text { Serum amyloid A } \\
\text { protein }\end{array}$ & $\begin{array}{c}\text { Immune } \\
\text { system process }\end{array}$ & & Transporter & 0.4742 & 0.0319 \\
\hline 35 & 9.46 & 5 & P10720 & $\begin{array}{c}\text { Platelet factor } 4 \\
\text { variant }\end{array}$ & $\begin{array}{c}\text { Blood } \\
\text { coagulation }\end{array}$ & & $\begin{array}{c}\text { Transfer/carrier } \\
\text { protein }\end{array}$ & 0.4742 & 0.5105 \\
\hline 36 & 53.31 & 29 & P02774 & $\begin{array}{c}\text { Vitamin } \\
\text { D-binding protein }\end{array}$ & Transport & & $\begin{array}{c}\text { Transfer/carrier } \\
\text { protein }\end{array}$ & 0.4831 & 2.2287 \\
\hline
\end{tabular}

${ }^{\mathrm{a}}$ Unused > 1.3 means at least $95 \%$ confidence; ${ }^{b}$ number of peptides with 95\% confidence; AAD: acute aortic dissection; AMI: acute myocardial infarction; CON: normal control.

in serum levels of candidate proteins between AAD patients and normal subjects. Thus, only twofold changes below or above normal controls were considered significant. In our study, total of 155 proteins had a relative difference between AAD patients and healthy volunteers. Therefore, with higher specificity, these candidate proteins are more likely to be potential biomarkers for AAD.

In the group of significantly increased proteins, there were numerous acute phase reactants, such as Beta-2-microglobulin (P61769), which could be indicative of an increased inflammatory response among AAD patients. CRP (P02741), a protein found to be elevated in patients who presented with symptoms or rupture of AAD and abdominal aortic aneurysm, was also identified using iTRAQ [11, 12]. CRP is a nonspecific biomarker associated with $\mathrm{AAD}$ and a predictor for long-term adverse events [13], and it can be used to monitor evolution of false lumen thrombosis [14]. Unfortunately, CRP is also produced in coronary plaques [15], acute myocardial infarction [16], and so forth. The elevations of these acute phase reactants represent a generalized reaction to vascular injury, and as such, they are nonspecific biomarkers. In addition, many proteins identified are associated with blood coagulation and fibrinolytic system. Among which, ten had increased serum levels 
(e.g., P00450-Ceruloplasmin, P02751-Fibronectin, P00738Haptoglobin...), and twelve had decreased serum levels (e.g., P02671-Fibrinogen alpha chain, P00751-Complement factor B, P00734-Prothrombin...). The pathophysiological mechanism for the appearance of these proteins may be explained by the release of tissue factors from the dissected aortic wall then the activation of the extrinsic coagulation system [17-19]. In addition, platelets can be activated by injuries to the vessel wall, activation of the coagulation cascade, or by activating factors released from stimulated endothelial cells and platelets (e.g., ADP, thromboxane, von Willebrand Factor). It also has been found that platelet functions were affected secondary to acute massive consumption coagulopathy in the false lumen in AAD patient $[20,21]$.

In the past few years, extracellular matrix (ECM) components of vessel walls such as elastin have been shown to be elevated in aortic dissections; however, such increases were less than twofold [3]. Our study found 9 extracellular matrix component proteins with greater than twofold differences, among these are Carboxypeptidase (P22792), Lumican (P51884), Fibronectin (P02751), Ceruloplasmin (P00450), and Thrombospondin-1 (TSP-1, P07996). Fibronectin is a polymorphic and multifunctional glycoprotein that plays wide-ranging roles in tissue injury [22-25]. TSP-1, which is an extracellular protein that participates in cell-to-cell and cell-to-matrix communication, can stimulate or inhibit the migration of vascular smooth muscle cells or endothelial cells. It has been known as a plasma marker of peripheral arterial disease [26].

Lumican is distributed in interstitial collagenous matrices throughout the body. In coronary arteries ischemic lesion, it is overexpressed by vascular smooth muscle cells (VSMCs) [27] and also synthesized in aortic smooth muscle cells [28]. In iTRAQ analysis, serum Lumican levels in patients with AAD were 1.29-fold and 3.63-fold higher than in patients with AMI and normal controls, respectively. It is interesting to note that with ITRAQ analysis, the level of difference between AAD and AMI for Lumican is less than that of Fibronectin (Table 2), yet the initial validation using ELISA method showed that only Lumican was significantly increased in AAD and AMI samples. While there may be variety reasons to explain the variations of the findings between the two methods, it highlights the importance of validation in biomarker studies. The finding that Lumican expression correlated with the time from onset to admission only in AAD but not in AMI sample further confirmed the specificity of this protein in association with AAD.

Proteomic approach provides an exciting platform to identify clinically useful protein biomarkers. As an initial step our study identified potential candidate protein biomarkers in the serum of AAD patients with the ITRAQ technique. However, the ultimate development of biomarkers which provide sufficient sensitivity or specificity for the diagnosis of AAD will require multiple validations and clinical testing, which may include nonprotein markers. Nevertheless our findings provide preliminary list of candidate biomarkers that should be further validated, either alone or in combination.

\section{Conclusion}

In this paper, we found that iTRAQ technique is a suitable approach for the detection of the new potential protein markers in the serum of AAD patients. Using iTRAQ approach, our study identified that Lumican may be a potentially interesting new serum marker of $\mathrm{AAD}$, and upon further validation this marker may assist the clinical diagnosis of AAD.

\section{Acknowledgments}

This study was supported by Shanghai Committee of Science and Technology (114119a9000). The authors also thank the Department of Chemistry and the Institute of Biomedical Science, Fudan University, Peoples Republic of China, for providing support for the project.

\section{References}

[1] J. A. Elefteriades, P. W. Barrett, and G. S. Kopf, "Litigation in nontraumatic aortic diseases: a tempest in the malpractice maelstrom," Cardiology, vol. 109, no. 4, pp. 263-272, 2008.

[2] T. Suzuki, A. Distante, and K. Eagle, "Biomarker-assisted diagnosis of acute aortic dissection: how far we have come and what to expect," Current Opinion in Cardiology, vol. 25, no. 6, pp. 541-545, 2010.

[3] T. Shinohara, K. Suzuki, M. Okada et al., "Soluble elastin fragments in serum are elevated in acute aortic dissection," Arteriosclerosis, Thrombosis, and Vascular Biology, vol. 23, no. 10, pp. 1839-1844, 2003.

[4] K. L. M. Boylan, J. D. Andersen, L. B. Anderson, L. Higgins, and A. P. N. Skubitz, "Quantitative proteomic analysis by iTRAQ for the identification of candidate biomarkers in ovarian cancer serum," Proteome Science, vol. 8, article 31, 2010.

[5] M. Latterich, M. Abramovitz, and B. Leyland-Jones, "Proteomics: new technologies and clinical applications," European Journal of Cancer, vol. 44, no. 18, pp. 2737-2741, 2008.

[6] X. Song, J. Bandow, J. Sherman et al., "iTRAQ experimental design for plasma biomarker discovery," Journal of Proteome Research, vol. 7, no. 7, pp. 2952-2958, 2008.

[7] V. Kolla, P. Jenö, S. Moes et al., "Quantitative proteomics analysis of maternal plasma in Down syndrome pregnancies using isobaric tagging reagent (iTRAQ)," Journal of Biomedicine \& Biotechnology, vol. 2010, Article ID 952047, 10 pages, 2010.

[8] S. G. Chee, K. C. Poh, K. P. Trong, and P. C. Wright, "Technical, experimental, and biological variations in isobaric tags for relative and absolute quantitation (iTRAQ)," Journal of Proteome Research, vol. 6, no. 2, pp. 821-827, 2007.

[9] M. Magharious, P. M. D'Onofrio, A. Hollander, P. Zhu, J. Chen, and P. D. Koeberle, "Quantitative iTRAQ analysis of retinal ganglion cell degeneration after optic nerve crush," Journal of Proteome Research, vol. 10, no. 8, pp. 3344-3362, 2011.

[10] Z. Zhang, L. Zhang, Y. Hua et al., "Comparative proteomic analysis of plasma membrane proteins between human osteosarcoma and normal osteoblastic cell lines," BMC Cancer, vol. 10 , article 206, 2010.

[11] S. Trimarchi, G. Sangiorgi, X. Sang et al., "In search of blood tests for thoracic aortic diseases," Annals of Thoracic Surgery, vol. 90, no. 5, pp. 1735-1742, 2010. 
[12] H. Domanovits, M. Schillinger, M. Müllner et al., "Acute phase reactants in patients with abdominal aortic aneurysm," Atherosclerosis, vol. 163, no. 2, pp. 297-302, 2002.

[13] K. Sakakura, N. Kubo, J. Ako et al., "Peak C-reactive protein level predicts long-term outcomes in type B acute aortic dissection," Hypertension, vol. 55, no. 2, pp. 422-429, 2010.

[14] S. Makita, A. Ohira, R. Tachieda et al., "Behavior of C-reactive protein levels in medically treated aortic dissection and intramural hematoma," American Journal of Cardiology, vol. 86, no. 2, pp. 242-244, 2000.

[15] K. Yasojima, C. Schwab, E. G. McGeer, and P. L. McGeer, "Generation of C-reactive protein and complement components in atherosclerotic plaques," American Journal of Pathology, vol. 158, no. 3, pp. 1039-1051, 2001.

[16] T. Celik, A. Iyisoy, H. Kursaklioglu, H. Turhan, and E. Isik, "Does the pre-existing inflammation play a role in the increased C-reactive protein levels in acute myocardial infarction?" International Journal of Cardiology, vol. 112, no. 1, pp. 134-135, 2006.

[17] J. Vandercappellen, J. Van Damme, and S. Struyf, “The role of the CXC chemokines platelet factor-4 (CXCL4/PF-4) and its variant (CXCL4L1/PF-4var) in inflammation, angiogenesis and cancer," Cytokine and Growth Factor, vol. 22, no. 1, pp. 1$18,2011$.

[18] P. Blair and R. Flaumenhaft, "Platelet $\alpha$-granules: basic biology and clinical correlates," Blood Reviews, vol. 23, no. 4, pp. $177-$ 189, 2009.

[19] S. Struyf, M. D. Burdick, P. Proost, J. Van Damme, and R. M. Stricter, "Platelets release CXCL4L1, a nonallelic variant of the chemokine platelet factor-4/CXCL4 and potent inhibitor of angiogenesis," Circulation Research, vol. 95, no. 9, pp. 855-857, 2004.

[20] G. Shi and C. N. Morrell, "Platelets as initiators and mediators of inflammation at the vessel wall," Thrombosis Research, vol. 127, no. 5, pp. 387-390, 2011.

[21] M. Tanaka, K. Kawahito, H. Adachi, and T. Ino, "Platelet dysfunction in acute type A aortic dissection evaluated by the laser light-scattering method," Journal of Thoracic and Cardiovascular Surgery, vol. 126, no. 3, pp. 837-841, 2003.

[22] D. J. Romberger, "Fibronectin," The International Journal of Biochemistry \& Cell Biology, vol. 29, no. 7, pp. 939-934, 1997.

[23] J. H. Peters, M. N. Grote, N. E. Lane, and R. J. Maunder, "Changes in plasma fibronectin isoform levels predict distinct clinical outcomes in critically III patients," Biomarker Insights, vol. 6, pp. 59-68, 2011.

[24] S. Lucena, C. L. Arocha Piñango, and B. Guerrero, "Fibronectin. Structure and functions associated to hemostasis. Review," Investigacion Clinica, vol. 48, no. 2, pp. 249-262, 2007.

[25] C. Örem, S. O. Çelik, A. Örem, M. Calapolu, and C. Erdöl, "Increased plasma fibronectin levels in patients with acute myocardial infarction complicated with left ventricular thrombus," Thrombosis Research, vol. 105, no. 1, pp. 37-41, 2002.

[26] D. M. Smadja, C. D’Audigier, I. Bièche et al., "Thrombospondin-1 is a plasmatic marker of peripheral arterial disease that modulates endothelial progenitor cell angiogenic properties," Arteriosclerosis, Thrombosis, and Vascular Biology, vol. 31, no. 3, pp. 551-559, 2011.

[27] H. Qin, T. Ishiwata, and G. Asano, "Effects of the extracellular matrix on lumican expression in rat aortic smooth muscle cells in vitro," Journal of Pathology, vol. 195, no. 5, pp. 604-608, 2001.
[28] Z. Naito, "The role of small leucine-rich proteoglycan (SLRP) family in pathological lesions and cancer cell growth," Journal of Nippon Medical School, vol. 72, no. 3, pp. 137-145, 2005. 

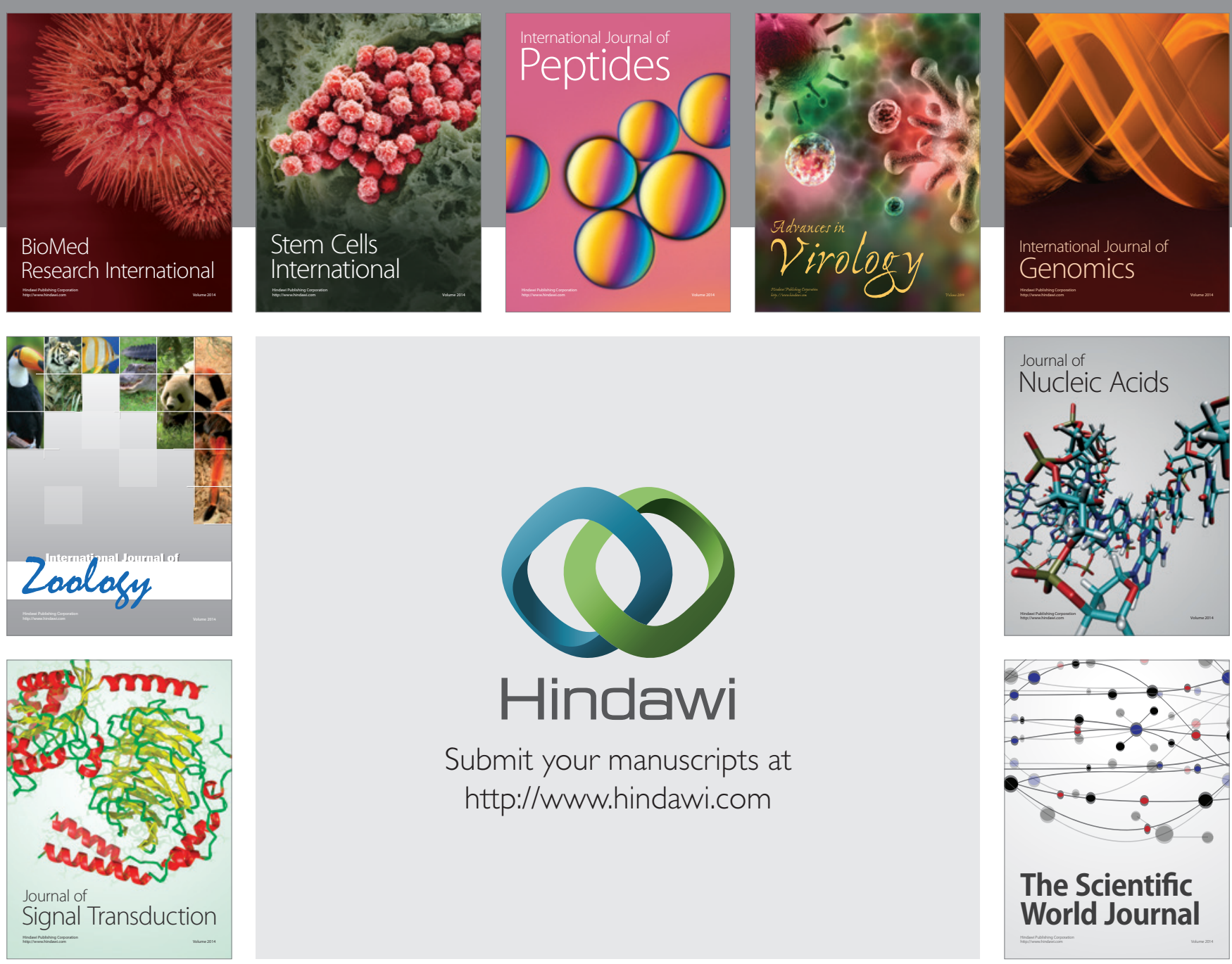

Submit your manuscripts at

http://www.hindawi.com
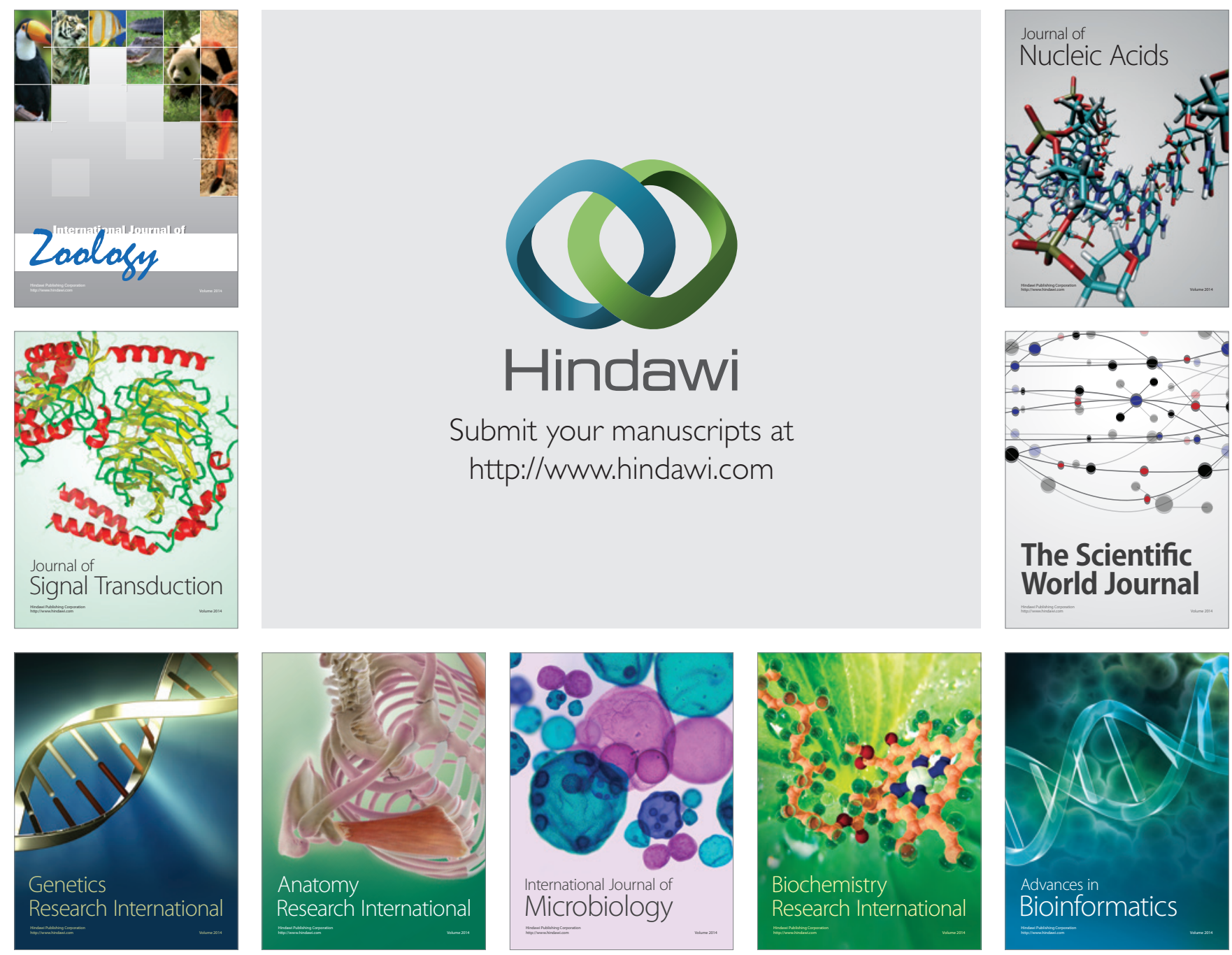

The Scientific World Journal
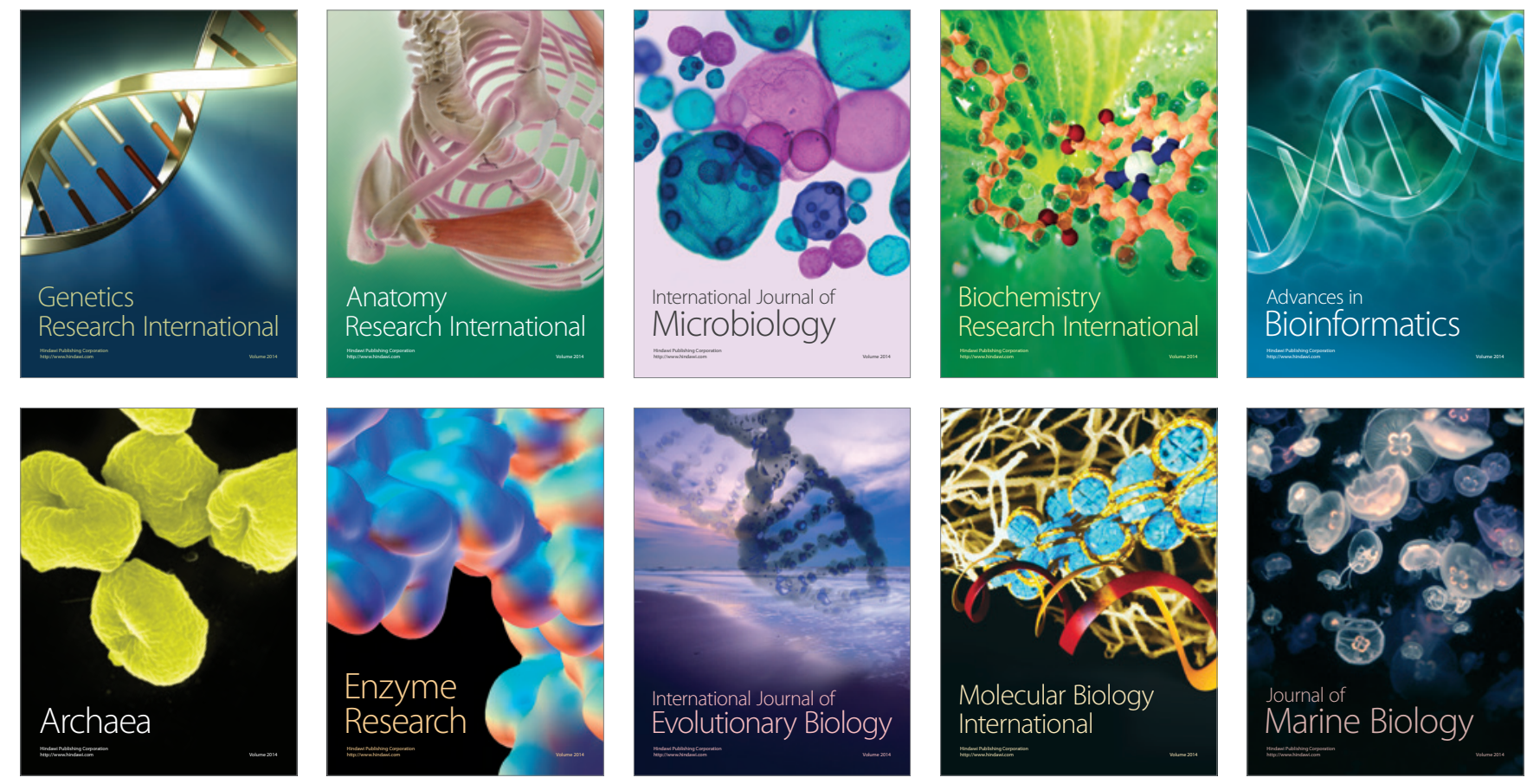